\title{
QUANTO SIGNIFICAM AS CONSTRUÇÕES? SENTIDOS DE FORMAS DE CLASSES FECHADAS
}

\author{
Konrad Szcześniak
}

\begin{abstract}
RESUMO
Este trabalho concentra-se na questão de sentidos de construçóes gramaticais no âmbito da Gramática de Construçóes. Argumenta-se que a tese simbólica, que prevê sentidos em todas as formas linguísticas, foi levada longe demais em muitas análises de construçóes gramaticais. Sentidos atribuídos a algumas construçóes na literatura cognitiva são implausíveis — muito ricos para formas de classes fechadas.
\end{abstract}

PALAVRAS-CHAVE: construçóes gramaticais; tese simbólica; distinção léxico-sintática.

\section{Introduçáo}

radicionalmente, costumava-se assumir que a linguagem segrega suas formas em duas superclasses gerais. A primeira conteria categorias lexicais

como substantivos ou adjetivos, ou seja, formas com sentidos ricos. $\mathrm{Na}$ outra, incluíam-se categorias gramaticais tais como artigos, pronomes ou conjunções - classes que não têm sentidos, mas funções ou conteúdo relacional. A existência dessa divisão defende-se por meio de uma longa lista de características que distinguem as duas classes. Por exemplo, como sugerem os nomes "formas de classes abertas" (formas lexicais) e "formas de classes fechadas" (formas gramaticais), novos itens facilmente podem entrar no primeiro grupo, enquanto o grupo de classes fechadas resistem novos membros. Como consequência, as formas de classes abertas são muito mais numerosas, contendo dezenas de milhares de itens, do que formas de classes fechadas, cujos números não chegam a exceder algumas centenas. 
Recentemente, porém, a validade da distinção questionou-se especialmente na literatura cognitivista. Os primeiros sinais de problemas com a distinção surgiram já nos primeiros anos da Gramática Gerativa quando Chomsky reconheceu que expressôes idiomáticas não se encaixavam no modelo gerativo e resolveu "pôr de lado fenômenos que resultam do acidente histórico, mesclagem dialética, idiossincrasias pessoais e por aí fora” esperando que se expliquem mais tarde (CHOMSKY, 1995, p. 20). Depois, o trabalho sobre expressôes idiomáticas de Fillmore mostrou que apesar de sua forma locucional, trata-se de unidades irreduzíveis linguísticas que resistem explicaçâo por meio de princípios abstratos. Fillmore, Kay and O'Connor (1988) observaram que, por conseguinte, expressóes idiomáticas se assemelham a morfemas individuais e ao mesmo tempo a locuçóes livremente compostas governadas por regras sintáticas gerais. O problema que expressóes idiomáticas apresentam é que elas aparentemente não se podem colocar de qualquer lado da divisão léxico-sintática. A impressão de nebulosidade intensifica-se mais ainda com o fato de que expressóes idiomáticas não são um grupo homogêneo em si; exibem vários graus de esquematicidade, sendo algumas fortemente substanciais (compostas de material lexical fixo, como no caso de expressóes idiomáticas tais como dar o golpe de misericórdia ou mudar de ideias) e outras bastante esquemáticas e abertas, com "espaços em branco" a serem preenchidos de material lexical. Este conjunto de diversas formas léxico-sintáticas espalha-se pela divisão, o que pode ser considerado um argumento para questionar seu propósito, ou até mesmo a sua própria existência.

Tudo isso motivou a rejeição da divisão por linguistas representantes de vários modelos de gramática. Por exemplo, uma das principais suposiçóes da Gramática da Palavra de Hudson é a constatação que "não se supóe (nem se observa) qualquer distinção entre 'regras' e 'itens lexicais'." (HOLMES \& HUDSON, 2005, p. 243). A distinção encontra-se suspensa também no modelo da Gramática Sintagmática Nuclear (Head-driven Phrase Structure Grammar, HPSG) (POLLARD \& SAG, 1994), onde itens lexicais estão dotados de detalhadas informaçóes sobre suas propriedades semânticas e sintáticas. Culicover e Jackendoff (2005, p. 26) defendem que "a tradicional distinção entre o léxico e gramática é errônea." Em um outro trabalho, Jackendoff também chama a distinção léxico-gramatical de um "equívoco fundamental" (Jackendoff, 2007, p. 53). A nebulosidade da divisão é vista como um exem- 
plo de uma tendência mais geral segundo a qual os componentes linguísticos se fundem em vez de serem divididos de uma forma definida. É essa a posição assumida por Lewandowska-Tomaszczyk na sua análise de polissemia que é "exponente da ausência de um limite claro entre a semântica e pragmática (tal como entre o léxico e sintaxe...)” (2007, p. 154). A fronteira é também contestada na Gramática das Construções de Goldberg (1995, 2006) e na Gramática Cognitiva de Langacker (2008). As críticas proferidas por cognitivistas podem ser resumidas como a convicção de que a distinção é incompatível com a tese simbólica, segundo a qual construções trazem sentidos. Já que a distinção pressupóe uma austeridade semântica de elementos de classes fechadas, tais como construçóes gramaticais que evidente e inequivocamente têm conteúdo semântico, não é exagero concluir que a insistência teimosa na distinção pode ser um obstáculo para pesquisa sobre conteúdo semântico de construçôes. À luz desses problemas, parece perfeitamente razoável descartar a distinção. Assim, o ceticismo cognitivo face à separação do léxico e gramática é motivado pela visão da linguagem como composta por pareamentos entre forma e significado. Em resumo, ao permitir que elementos de classes fechadas possam ter significados, pode-se analisar "os pormenores da semântica e a distribuição de palavras, morfemas gramaticais, e raros conjuntos locucionais extraordinários." (GOLDBERG, 2006, p. 5)

Deste modo, a divisão tem sido abordada como um contínuo, uma solução defendida por Langacker (2008), Gentner \& Boroditsky (2001), Evans \& Green (2006) ou Ferrari (2010) que defende que "léxico e sintaxe não constituem módulos rigidamente separados, mas formam um continuum de construçóes, partindo de elementos muito específicos, como o item lexical cadeira ... até padróes mais abstratos, tais como a categoria 'verbo' ou a construção transitiva [SN1 V SN2].” (FERRARI, 2010, p. 149) Teoricamente, isso pode parecer um passo razoável, já que leva em conta a nebulosidade da fronteira, mas na prática, propostas de preservar a distinção como um contínuo não passam de meras declaraçóes ocas, e o compromisso de contínuo é explorado como pretexto para banir completamente a separação léxico-sintática. Atualmente, supóe-se que todas as formas são simbólicas em natureza (LANGACKER, 2008), e, por conseguinte, formas de classes fechadas deveriam ter qualquer tipo de significado. Isso é por vezes uma suposição implícita de várias análises construcionistas ou um manifesto aberto, como no caso de Kay e Michaelis 
que propóem que "provavelmente todo e qualquer tipo de significado que ocorre pode ser a contribuição semântica de uma construçăo." (2012: 2278)

Isto não quer dizer que a inteira comunidade linguística abandonasse a noção tradicional da separaçấo léxico-gramatical. $\mathrm{O}$ influente Sistema de Estruturação Conceitual de Talmy (2000) pressupóe uma divisão rigorosa entre os sistemas lexical e gramatical, sendo o primeiro responsável pelo conteúdo da representação cognitiva de uma frase, e o segundo pela estrutura da mesma. Boas (2010) repara que a análise de Goldberg (1995) se alicerça na pressuposição da existência de "pelo menos duas categorias distintas de informação linguística que interagem uma com a outra - nomeadamente entradas lexicais e construçôes de estrutura argumental." Boas acrescenta que "isto sugere uma separação de facto entre sintaxe e o léxico, apesar de suas afirmações que 'o léxico não está diferenciado ordenadamente do resto da gramática”' (GOLDBERG, 2006, p. 5). Como argumenta Van Valin (2006), a alegação que tudo constitui uma construção tem pouca substância, tanto teórica como empírica.

O presente estudo procurará demonstrar que a divisão talvez fosse rejeitada prematuramente. Mesmo que o limite seja inerente e irreparavelmente nebuloso e não exista um meio prático de demarcar os dois magistérios, isto não é uma boa razão para abandonar a distinção. Apontar a nebulosidade da divisão é uma coisa, e concluir que isso significa sua ausência é outra. Tomar esse caminho é cometer a falácia de contínuo. Trata-se de um erro de raciocinar que dois extremos devem ser idênticos se eles se encontram conectados por pequenas diferenças intermédias e se não se pode indicar um ponto de diferença decisiva. Por exemplo, a impossibilidade de apontar a que temperatura água fria se torna quente não nos deveria levar a concluir que a frio é a mesma coisa que o quente. Mas é o que acontece quando a nebulosidade da distinção léxico-sintática é usada como uma justificação para tratar todas as formas linguísticas como construçóes dotadas de potencialidades semânticas iguais.

Neste trabalho, parto do pressuposto que uma distinção nebulosa é melhor do que uma distinçáo inexistente. Continuam válidas as premissas (associadas com a distinção tradicional) que elementos de classes fechadas têm funçóes, não significados; isto é, embora se possa demonstrar que esses elementos tenham significados, tais significados sáo sujeitos a limitaçóes. Autores trabalhando no âmbito da Gramática de Construçôes atribuem significados bastante complexos e ricos a construçôes gramaticais tais como the way cons- 
truction (He has shot his way to immortality) ou a construção de incredulidade (Ele dirigir?! Ele não tem carteira de habilitação.). No caso de construçôes gramaticais esquemáticas (elementos de classes fechadas) é preciso verificar os efeitos semânticos e pragmáticos, já que é pouco plausível que esses efeitos excedam as potencialidades de classes fechadas. Como vou procurar mostrar no resto do texto, muitos desses efeitos floridos não passam de interpretaçóes contextuais de sentidos muito mais básicos e simples que uma construção é capaz de exprimir.

O presente estudo vai se concentrar em construçóes analisadas no âmbito da Gramática de Construções ( $\mathrm{CxG}$ ). Consoante com a tradição da $\mathrm{CxG}$, vamos seguir a tese simbólica e a afirmação partilhada por muitos e expressa explicitamente por Fried e Östman (2004, p. 24) que a "gramática é composta de associações convencionais de forma e significado", com base na definição de construçôes como "pareamentos de forma e significado" (GOLDBERG, 2006, p. 5). As construçóes apresentadas aqui não podem ser governadas por regras sintáticas gerais, e deste modo, encaixam-se na definição de construçôes como "pareamentos de forma e significado que são pelo menos em parte arbitrários” (CROFT, 2001, p. 18). Neste sentido, conjuntos sintáticos como "the way construction" ou "the time away construction" são autênticas construçôes (em vez de serem instâncias especiais de umas regras mais gerais) e devem ser armazenadas como entradas no léxico, ou seja, no constructicon (GOLDBERG, 2006). Os efeitos semânticos apresentados abaixo são fortes o suficiente para merecer uma abordagem construcional.

No entanto, embora a análise subscreva a perspectiva de construçóes sintáticas como elementos portadores de sentido, o presente estudo defende que sentidos de construçôes gramaticais são constrangidos pelas consideraçôes formais. Quanto mais esquemática é uma construção, mais provável é que tenha propriedades de formas de classes fechadas. Quanto mais material lexical pré-inserido faz parte de uma construção, mais rico será seu sentido. A hipótese central do presente estudo é que muitos sentidos imputados a várias construçóes gramaticais são implausivelmente ricos e em muitos casos, se pode demonstrar que os efeitos rebuscados não passam de inferências contextuais em vez de serem o inerente conteúdo da própria construção. Um objetivo desta abordagem é analisar os efeitos semânticos das construçôes mais moderados sem suspender a divisão léxico-sintática que pressupóe um grau de austeridade 
semântica de formas funcionais associadas com a sintaxe. Nas seguintes seçóes, vamos considerar três construçóes que têm equivalentes próximos em português e inglês, com o intuito de demonstrar que em ambas as línguas, as construçôes têm sentidos bem mais gerais do que se pode supor à primeira vista.

\section{Sentidos menos complexos do que parecem à primeira vista}

\section{Construçấo de incredulidade}

Um elemento de classes fechadas ao qual se atribui um considerável conteúdo semântico é a chamada construção de incredulidade, apontada pela primeira vez por Akmajian (1984). As seguintes frases são exemplos de uso dessa construção:

(1) a. Ela vegetariana?

O que, eu me preocupar? (What, me worry? exemplo la em (Akmajian, 1984))

Ele acordar cedo?

Eles entender física nuclear?

À primeira vista, a construção parece exprimir sentidos sugeridos no seu nome. O efeito que ela transmite é o de uma reação emocional enfática face à proposição expressa no predicado. Nos exemplos acima, podemos imaginar que o locutor tem graves dúvidas acerca da ideia de que a mulher seja vegetariana (1a) ou que as pessoas em (1d) tenham as competências para lidar com a física nuclear. É preciso salientar que se trata de uma construção plenamente esquemática: a forma deste padrão não contém elementos pré-inseridos; é composta somente por espaços a preencher com o sujeito e verbo ou objeto. Ao mesmo tempo, a construção tem uma forma singular que a distingue de frases afirmativas. A construção de incredulidade guarda a peculiaridade de que o verbo não é conjugado, mas sim aparece no infinitivo. Por outras palavras, sendo um padrão esquemático, é um elemento de classes fechadas com um significado bastante enfeitado típico de elementos de classes abertas.

Não é de admirar que assim esta construção é usada como uma espécie de símbolo da causa construcionista. O exemplo da incredulidade aparece em 
muitas análises (e.g., GOLDBERG, 2006; HUHMANN, 2008) como evidência de semântica extraordinária em construções gramaticais. Costuma-se argumentar que a construção de incredulidade exibe uma estrutura idiosincrática, tanto formal como semântica, o que, segundo proponentes da abordagem construcionista, é prova ideal da nebulosidade da divisão léxico-sintática. Lambrecht defende que "é impossível traçar uma linha divisória clara em termos de princípio entre padrōes 'altamente marcados' (ou 'idiomáticos') e os 'não marcados' (ou 'regulares'). A existência e estrutura da [construção de incredulidade] constitui uma prova a favor da abordagem 'construcionista' à sintaxe." (Lambrecht, 1990, p. 226) Kay afirma "forças pragmáticas ou efeitos de enunciados de tais expressóes obedecem a convenções linguísticas mais do que raciocínio inferencial (de implicatura conversacional) e, por conseguinte, devem ser captadas pela gramática.” (KAY, 1995, p. 124)

No entanto, se se olhar mais de perto, o conteúdo semântico da construção torna-se menos claro e, não obstante as afirmaçóes de Kay, os efeitos em causa podem resultar através do processo de raciocínio inferencial.

É pouco provável que incredulidade seja a verdadeiro sentido da construção, quando se considerar outras funçóes que a construção pode ter. Uma delas é expressão de divertimento, como no seguinte exemplo.

(2) Woody Allen... halterofilista?

Diferente de incredulidade, divertimento não tem que implicar rejeição da proposição contida no enunciado - podemos ficar admirados e achar engraçado o fato de Allen frequentar o ginásio. Adicionalmente, o cenário é bastante diferente, já que divertimento é uma reação mais reservada e distante, enquanto incredulidade é mais emocionada.

Embora seja necessário admitir a possibilidade de incredulidade e divertimento serem variaçóes do mesmo tema, existem deviaçóes mais sérias da interpretação clássica de incredulidade. Nos exemplos abaixo (3a-b), o locutor não pode esconder a surpresa ou até mesmo a admiração, que são relaçôes emotivas distintas da incredulidade, porque elas pressupóem a admissão da proposição. O locutor não questiona os fatos, só exprime admiração (3a) ou surpresa, talvez ironia (3b). 
(3) a. Ele doutor? Raios me partam!

b. A Joana lavar a louça? É impressionante!

Além disso, a construção pode ser utilizada para exprimir protesto, como nos exemplos (4a-b).

(4) a. Eu roubar seu dinheiro? (Como você se atreve?!)

b. Meu pai assaltar um posto de gasolina?! (Você está doido?)

O que distingue esses exemplos de usos "típicos" analisados na literatura é que em enunciados de protesto (4a), dificilmente se defenderia que o locutor exprima ceticismo. No caso, ocorre uma rejeição da proposição, mas não se trata de um cenário em que o locutor faça uma autodescoberta, reagindo com incredulidade. Diferente de muitos outros casos de emprego da construção, aqui nem há espaço para incredulidade, já que essa normalmente surge em situaçôes onde a veracidade de uma proposição é avaliada e é considerada pouco provável; na situação (4a) a veracidade da proposição não é questão de dúvida, crença ou opinião. Assim, enquanto usos "típicos" da construção se poderiam parafrasear através de construçôes como "Não acredito que ele seja doutor, entenda física, etc.", aqui seria muito esquisito exprimir incredulidade dizendo "Não acredito eu roubasse seu dinheiro."

Em resumo, além da interpretação de incredulidade, podem-se observar outros sentidos expressos através da construção: divertimento, admiração, e protesto são provavelmente só alguns significados possíveis de exprimir com a construção. E ainda por cima, esses efeitos poderiam teoricamente ser trocados por entre as frases. Por exemplo, em (2) a intenção do locutor poderia ser a de exprimir admiração e em (4), em vez de manifestar protesto, o locutor poderia também transmitir sarcasmo divertido. Parece que a interpretação exata depende de fatores como contexto, intoação, conhecimento de fundo e assim por diante.

Uma análise alternativa da contribuição semântica da construção poderia ser a hipótese de que a função desse padrão sintático é destacar a incongruidade dos fatos mencionados na frase. É possível que a ênfase da incongruidade seja realizada através da forma da construção: diferente de frases afirmativas onde o sujeito é seguido de um predicado, aqui o sujeito se encontra separado 
do resto da frase constituída por um verbo não conjugado ou um objeto sem verbo. Assim, a forma da construção sinaliza uma falta de transição macia entre as duas partes da preposição que estão sendo apresentadas como incongruentes. $\mathrm{O}$ efeito de separação entre o sujeito e o verbo é ainda mais forte em inglês, onde a construção utiliza um sujeito acusativo em vez nominativo como seria de costume:

(5) a. Him be an engineer?

Ele- ${ }_{\text {ACC }}$ ser ART engenheiro?

b. Me be a priest?

Me ser ART padre?

De fato, este padrão com o sujeito separado do verbo observa-se em muitas línguas. Em polonês, como em português, o sujeito é seguido de infinitivo ou diretamente de objeto, quando o verbo for ser. A única diferença é que em polonês, a separação é reforçada pelo uso da conjunção coordenativa $i$ ('e')

(6) On i lekarz?

Ele e- doutor?

'Ele doutor?'

O mesmo se dá em alemão, onde a construção também inclui a conjunção coordenativa:

(7) a. Du und Arzt?

Você e- doutor?

'Você doutor?'

b. Ich und arbeiten?

Eu e- trabalhar?

'Eu trabalhar?'

\section{A construção give-gerund / dar-substantivo-ada}

Tal como a construção de incredulidade, a construção que se segue também parece, à primeira vista, ter um significado bastante estreito para uma 
forma de classes fechadas, e é assim que ela é descrita na literatura. As frases em (8) são exemplos de uso de predicados compostos give-gerund ('dar-gerúndio'), uma construção que ocorre tanto no português (8a-c) como no inglês (8d-f). A diferença consiste no fato de que no caso da construção inglesa se utilizam verbos em forma de gerúndio (daí o nome give-gerund) e no caso do equivalente português, em vez do gerúndio o verbo dar é seguido de um substantivo que termina em -ada (dar-substantivo-ada).

(8) a. O dito José ... deu the uma pancada leve na mão com tamanco. (Marcus Aurelio Taborda de Oliveira, Educação do corpo na escola brasileira)

b. E o meu avô deu-lhe uma cabeçada (Alves Redol, O Muro branco)

c. Ao dizer isto o meu pai deu-me uma bofetada que me derrubou. (Jorge Almeida, Evangelho de Madalena e outros contos)

d. The patrol officer tried to pin down his arms so that his comrade could give him a good battering.

e. We go in there and give them a kicking.

f. I have a good mind to walk out there and give you a sound licking.

A semelhança entre as versôes inglesa e portuguesa é evidente na seguinte fórmula que resume as formas da construçấo nas respectivas línguas:

(9) a. give PRO ART-INDEF (ADJ) gerúndio

b. dar PRO ART-INDEF (ADJ) subst-ada

Predicados compostos give-gerúndio são um subconjunto de construçôes de verbos leves que se caracterizam por um largo denominador comum semântico. No entanto, diferentemente da supercategoria à qual pertencem, predicados compostos com o verbo give / dar, segundo alguns autores, têm um sentido especializado. Kearns (2002) defende que tais usos denotam açóes a ver com "dano corporal", uma observação que parece ser consistente com frases enumeradas acima. A observação de Kearns parece ter ainda mais peso se considerarmos um considerável número de substantivos que aparecem na construção portuguesa com o sentido de dano corporal: 
(10) dar uma pancada, bofetada, dar bordoada, cabeçada, topada, porrada, palmada, cajadada, cotovelada, facada, tacada, chicotada, chinelada, navalhada, joelhada, sovada, batida etc.

Em inglês também, a construção envolve quaisquer verbos com o sentido 'bater' (lash, belt, thrash, smack, cane). Isso provoca a impressão de que a construção se especializa de fato em expressão de dano corporal. Às vezes, o dano pode ser interpretado metaforicamente. Por exemplo, Trousdale (2008) argumenta que "há um subconjunto considerável de predicados compostos give-gerúndio que não envolvem dano corporal em si, mas castigação verbal..." (p. 41), como nos exemplos abaixo.

(11) a. She gave me a severe tongue lashing.

b. I'm going to give him a good chewing out when I get home!

c. The police gave the child a stern talking to.

Contudo, Trousdale observa que, além do grupo de verbos com sentidos de dano corporal e castigação verbal, existem também usos cuja associação com violência física é mais tênue. Alguns usos são ambíguos, como no seguinte caso, onde a interpretação pode ser ou 'bater' ou 'ter relação sexual':

(12) I'll give her a seeing to. (TROUSDALE, 2008, p. 35)

Além disso, há exemplos em inglês nos quais o objeto é submetido a uma ação de esforço físico ou um processo:

(13) a. If the bushes block your front windows, give them a good pruning. $b$. You can soak the beans overnight and give them a good shaking in a sieve or strainer.

$c$. She gave the shirt a quick ironing.

d. Give the lawn a thorough soaking.

e. I asked Clement to ... dig out my old beaver hat and give it a brushing down (Mick Jackson, The Underground Man) 
Se esses usos têm algo em comum, é só o fato de o objeto ser afetado pela ação, um elemento semântico bastante geral e muito típico de formas de classes fechadas. Ser submetido a um processo e ficar afetado é um tema recorrente em muitas categorias gramaticais como o caso acusativo (DOWTY, 1991), construção resultativa (LEVIN \& RAPPAPORT HOVAV, 1993) ou o dativo malefativo (JANDA, 1993) (WIERZBICKA, 1988) utilizado nos seguintes exemplos de polonês, checo, e português:

(14) a. Matka mi umarła.

Mãe a.mim morreu

'Minha mãe morreu.' (WIERZBICKA, 1988: 212)

b. Ditě nam v noci plače.

Bebê.nom a.nós na noite.loc chora

'Nosso bebê chora durante a noite (e isso nos afeta).' (JANDA, 1993: 85)

c. Fanou-lhe a namorada.

Em português também ocorrem na construção substantivos que não têm a ver com dano corporal:

(15) dar uma arrancada, olhada, parada, passada, pensada, tossida etc.

Embora muitos usos da construção, tanto em inglês como em português, pareçam no início ser dedicados a um conteúdo semântico restrito, uma análise de um maior número de usos revela que em termos semânticos a construção não se distingue muito de outras formas de classes fechadas.

\section{A construção de avaliação moral}

A primeira vista, a seguinte construção também se mostra como sendo uma construção esquemática com um significado extraordinariamente rico. A construção que se pode denominar como construção de avaliação moral parece servir para exprimir julgamentos morais subjetivos de comportamento das pessoas. Os exemplos (16) mostram que a construção é utilizada para dar sua opinião de açóes descritas na oração subordinada. 
(16) a. Foi muito simpático da sua parte ajudar-nos a resolver os problemas financeiros.

b. É também um erro crasso da tua parte não teres feito as contas.

c. Foi muito feio mesmo da parte dele vir e acusar-te de roubar o dinheiro arrecadado da associação.

d. ...considero pouco elegante da parte do colega não ter falado conosco pessoalmente antes de fazer acusaçóes infundadas.

e. Foi descuidado da minha parte tomar os remédios sem ler as instruções.

f. Foi mal educado da tua parte interromper o professor.

g. Acho egoísta e horrível da parte dele comprar um carro com o dinheiro que ela poupava há anos.

O que intensifica a impressão de que a construçâo se dedica a julgamentos morais é o fato de a avaliação ser ou claramente negativa ou positiva. Dificilmente se encontram exemplos de frases que descrevam comportamentos moralmente neutros.

(17) É aceitável da sua parte deixar a casa.

Além disso, não é suficiente que frases baseadas na construção exprimam julgamentos positivos ou negativos; as avaliaçóes devem ser de uma natureza moral. Por conseguinte, frases como (18) que não exprimem julgamento moral são inaceitáveis.

(18) *Foi rápido da parte dele chegar a horas.

É interessante acrescentar que essa regularidade também se aplica a outras línguas e assim os exemplos em (18) são inaceitáveis não só em português, mas também em inglês, francês e polonês:

(19) a. *Foi bem inábil da parte da Rita que ela massacrou a pronúncia assim tão mal.

a. ${ }^{*}$ It was unqualified of Rita to butcher the pronunciation so badly. 
b. *C'était inadequat de la part de Rita de massacrer la prononciation comme ça.

d. *(To) nieumiejętne ze strony Rity, że tak bardzo kaleczyła wymowę.

Porém, há uma diferença entre a construção em inglês e os equivalentes em português e francês. A versão inglesa da construção é um padrão quase completamente geral, com o pronome it e a preposição of sendo os únicos elementos fixos pré-inseridos na forma da construção, enquanto em português a construção também inclui a oração da parte de (alguém) (em francês de la parte de e em polonês ze strony). Essa diferença tem consequências interessantes, já que esse material lexical adicional aumenta o potencial semântico da construção nessas línguas, em relação ao inglês. Como consequência, em português (tal como francês e polonês) a construção é mais seletiva em relação a verbos que podem fazer parte de uma frase construída à base da construção, enquanto em inglês, a construção está disponível a muito mais verbos, como nos seguintes exemplos:

(20) a. It was strange of him to lock the door.

b. It was necessary of him to win the game.

c. It was unbelievable of her to miss the Paris trip just because her mom was bugging her. (http://babysittersclub.proboards.com accessed September 12, 2012)

d. It was extraordinary of her to allow grief to numb her this way, but then she grieved for a rather extraordinary man. (D. Nicholas, Silent Sonata, 12)

e. I don't think it was hasty of you to decide to get married. (M. Pearce, Cindy Jones)

f. It was rare-not unheard of, but rare- of him to burn a pot or let a dish go cold (...) (N. Roberts, Tears Of The Moon, 20)

Embora seja claro que a construção inglesa não é plenamente flexível quanto a tipos de julgamento que ela permite transmitir, ela não está limitada a avaliaçôes morais. Já no caso da versão portuguesa, parece haver a necessidade de o adjetivo se referir a julgamentos de uma natureza moral. Isso é consequência da presença do material lexical (da parte de) na construção - em geral, 
quanto mais inserçóes fixas fazem parte de uma construção, mais se assemelha a expressóes idiomáticas com propriedades de classes abertas.

\section{Conclusões}

Um balanço cético de construçóes assim poderia continuar interminavelmente, revistando muito mais exemplos de padrôes sintáticos, e um por um, mostrando que eles não passam de típicos elementos funcionais bem-comportados com significados esquemáticos como qualquer outro elemento de classes fechadas. De fato, tais contestaçóes foram realizadas em outros trabalhos, como por exemplo, na análise da construçâo x’s way (Szcześniak, 2013) que mostra que a interpretação de dificuldade de movimento atribuída a essa construção é somente uma inferência contextual, uma vez que o padrão verbo PRo way muitas vezes transmite progresso desenfreado, sem qualquer alusão a obstáculos ao movimento. No entanto, isso não quer dizer que nenhum padrão seja capaz de exprimir sentidos mais complexos. Existem formas intermédias entre elementos de classes fechadas e abertas, que incluem algum material lexical, como no caso da versão portuguesa da construção de avaliação moral, que contribuem um conteúdo semântico mais rico do que seria possível no caso de formas completamente abstratas. Dessa abordagem decorre o corolário de que sentidos mais ricos observados em padróes sintáticos deveriam ter origem nas inclusóes lexicais que fazem parte desses padróes, e assim deveria ser possível apontar uma associação entre um sentido extraordinário da construção e o material lexical que é responsável por esse efeito semântico.

\section{Referências}

AKMAJIAN, Adrian. 1984 Sentence Types and the Form-Function Fit. Natural Language and Linguistic Theory, 2, 1984. p. 1-23.

BOAS, Hans C. The syntax-lexicon continuum in Construction Grammar: A case study of English communication verbs. Belgian Journal of Linguistics 24, 2010. p. 54-82.

CHOMSKY, Noam. The Minimalist Program. Cambridge: MIT Press, 1995. CROFT, Willaim. Radical Construction Grammar. Syntactic Theory in Typological Perspective. Oxford: Oxford University Press, 2001. 
CULICOVER, Peter \& JACKENDOFF, Ray. Simpler Syntax. Oxford: Oxford University Press, 2005.

DOWTY, David. Thematic proto-roles and argument selection. Language, 67, 1991. p. 547-619.

EVANS, Vyvyan \& GREEN, Melanie. Cognitive Linguistics: An Introduction. Edinburgh: Edinburgh University Press, 2006.

FERRARI, Lilian. Modelos de gramática em linguística cognitiva: princípios convergentes e perspectivas complementares. Cadernos de Letras da UFF. Dossiê: Letras e cognição, 41, 2010. p. 149-165.

FILLMORE, Charles. J., KAY, Paul \& O'CONNOR, Mary C. Regularity and Idiomaticity in Grammatical Constructions: The Case of Let Alone. Language, 64, 1988. p. 501-538.

FRIED, Miriam, \& ÖSTMAN, Jan-Ola. Construction Grammar in a Cross-language Perspective. Amsterdam: John Benjamins, 2004.

GENTNER, Dedre \& BORODITSKY, Lera. Individuation, relativity and early word learning. In: M. Bowerman, \& S. Levinson, Language acquisition and conceptual development. Cambridge/New York: Cambridge University Press 2001. p. 215-256.

GOLDBERG, Adele. Constructions At Work: The Nature of Generalization in Language. Oxford: Oxford University Press, 2006.

. Constructions: A Construction Grammar Approach to Argument Structure. Chicago: The University of Chicago Press, 1995.

HOLMES, Jasper W. \& HUDSON, Richard. Constructions in word grammar. In: J.-O. Ostman, \& M. Fried, Construction grammars: Cognitive grounding and theoretical extensions. Amsterdam: John Benjamins, 2005. p. 243-272.

HUHMANN, Johannes. Parts of speech in Construction Grammar. Munich: GRIN Verlag, 2008.

JACKENDOFF, Ray. Language, Consciousness, Culture: Essays on Mental Structure. Cambridge, MA: MIT Press, 2007.

JANDA, Laura. A Geography of Case Semantics: The Czech Dative and the Russian Instrumental. Berlin: Mouton, 1993.

KAY, Paul. Construction Grammar. In J. Verschueren, J.-O. Östman, J. Blommaert, \& C. Bulcaen, Handbook of Pragmatics. Manual. Amsterdam: John Benjamins, 1995. p. 171-177. 
KAY, Paul \& MICHAELIS, Laura A. Constructional Meaning and Compositionality. In: C. Maienborn, K. von Heusinger, \& P. Portner, Semantics: An International Handbook of Natural Language Meaning: Volume 3. Berlin: Mouton de Gruyter, 2012. p.2271-2296

KEARNS, Kate. Light verbs in English. Ms., 2002 [1988].

LAMBRECHT, Knud. What, me, worry? Mad magazine sentences revisited. Berkeley Linguistics Society 16, pp. 215-228. Berkeley, CA: BLS, 1990.

LANGACKER, Ronald. W. Cognitive Grammar. A Basic Introduction. Oxford: Oxford University Press, 2008.

LEVIN, Beth, \& RAPPAPORT HOVAV, Malka. Unaccusativity At the Syntax-Lexical Semantics Interface. Cambridge, MA: MIT Press, 1993.

LEWANDOWSKA-TOMASZCZYK, Barbara. Polysemy, Prototypes, and Radial Categories. In: D. Geeraerts, \& H. Cuyckens, The Oxford Handbook of Cognitive Linguistics. Oxford: Oxford University Press, 2007. p. 139-169.

MAKKAI, Adam. Idiom structure in English. The Hague: Mouton, 1972.

POLLARD, Carl \& SAG, Ivan A. Head-Driven Phrase Structure Grammar. Chicago: The University of Chicago Press, 1994.

SCHLESINGER, Izchak M. Cognitive Space and Linguistic Case: Semantic and Syntactic Categories in English. Cambridge: Cambridge University Press, 2006.

SZCZEŚNIAK, Konrad. You can't cry your way to candy: Motion events and paths in the x's way construction. Cognitive Linguistics, 24(1), 2013. p. 159-194.

TALMY, Leonard. Toward A Cognitive Semantics. Volume I: Concept Structuring Systems. Cambridge, MA: MIT Press, 2000.

TROUSDALE, Graeme. Constructions in grammaticalization and lexicalization: Evidence from the history of a composite predicate construction in English. In: G. Trousdale, \& N. Gisborne (Eds.), Constructional Approaches to English Grammar. Berlin: Mouton de Gruyter, 2008. p. 33-70.

VAN VALIN, Robert. D. Review of Goldberg (2006). Journal of Linguistics 43, 2007. p. 234-240.

WIERZBICKA, Anna. The Semantics of Grammar. Amsterdam: John Benjamins, 1988. 


\title{
HOW MUCH DO CONSTRUCTIONS MEAN? MEANINGS OF CLOSED-CLASS FORMS
}

\begin{abstract}
The present contribution focuses on grammatical constructions within the framework of Construction Grammar. It is argued that the symbolic thesis, which assumes meanings in all linguistic forms, is being taken too far in many analyses of grammatical constructions. Meanings attributed to some constructions in the cognitive literature were implausibly rich for closed-class forms.
\end{abstract}

KEYWORDS: grammatical constructions; symbolic thesis; lexicon-syntax distinction; open-class forms, closed-class forms.

Recebido em 14/04/14 Aprovado em 05/06/14 